\title{
DESENVOLVIMENTO REGIONAL E A INFLUÊNCIA DA CIDADE DE CERES NO CERRADO GOIANO: SISTEMAS TÉCNICOS E A MODERNIZAÇÃO PRODUTIVA DO TERRITÓRIO ENTRE AS DÉCADAS DE 1960 E 1970
}

\author{
Regional development and Ceres influence in the Cerrado Goiano: technical systems and \\ the productive modernization of the region between the 1960 and 1970 decades
}

Wagner Abadio de Freitas *

Fernando Luíz Araujo Sobrinho**

Marcelo de Mello***

\begin{abstract}
*Acadêmico do PPG em Geografia - UnB - wagner.freitas@ifgoiano.edu.br. ** Docente do PPG em Geografia - UnB - flasobrinho@gmail.com.

** Docente da Universidade Estadual de Goiás - ueg.marcelo@gmail.com.
\end{abstract}

\begin{abstract}
Resumo: 0 presente trabalho visa abordar as repercussões produzidas no território goiano a partir da execução de Planos e Programas desenvolvidos e executados durante as décadas de 1960 e 1970. Estas intervenções foram orientadas pelo Estado e promoveram mudanças estruturais e conjunturais além de intensificar a articulação dos fluxos entre o litoral e o interior do país. Nessa perspectiva, a instalação de objetos técnicos foi essencial na redefinição da Divisão Territorial do Trabalho e afetou, em certa medida, o município de Ceres o que possibilitou o desenvolvimento regional do Estado de Goiás, tornando-o apto para a reprodução mais efetiva do capital. Por fim, a organização deste artigo foi pautada em pesquisas bibliográficas, análise documental, leis, decretos e tratamento de informações contidas em mapas editados durante a execução dos planos e programas.
\end{abstract}

Palavras-chave: Território; Planos e Programas; Desenvolvimento Regional.

\begin{abstract}
The current paper aims to discuss the repercussions ocured in the territory of Goias from the execution of Plans and Programs developed and executed during the 1960 and 1970 decades. These interventions were lead by the State government and promoted conjectural and structural changes, moreover it intensified the articulation of the flow between the coast and the interior of the country. From this perspective, the application of technical tools were essential in redefining the Territorial Division of Work and affected, in a certain way, the town of Ceres which made possible the regional development of the State of Goias, making itself fit for effective growth of capital. And last, this article was contucted based in bibliographical researches, document analyses, laws, decrees and working with information in maps edited during the execution of the plans and programs.
\end{abstract}

Key-words: Territory; Plans and Programs; Regional development.

\section{Introdução}

O presente trabalho visa abordar as repercussões produzidas no território goiano a partir da execução de Planos e Programas desenvolvidos e executados durante as décadas de 1960 e 1970. Neste período já era possível perceber que vários pontos do território estavam incorporados à dinâmica econômica comandada pela Região Concentrada. Estas intervenções afetaram o município de Ceres e foram essenciais na redefinição da Divisão Territorial do Trabalho e na aproximação e articulação dos fluxos entre o litoral e o interior do país. 
Este movimento, coordenado pelo Estado, tinha a intencionalidade em desenvolver as potencialidades existentes na região Centro-Oeste, tornando-a apta para a reprodução do capital. Para materializar esta intencionalidade alguns Planos e Programas orientaram o planejamento e as ações governamental. Vale destacar o Programa de Ação Econômica do Governo (1964-1966); o Plano Decenal de Desenvolvimento Econômico e Social (1967-1976) e o Programa Estratégico de Desenvolvimento (1968-1970).

Estas intervenções promoveram mudanças estruturais e conjunturais e uma progressiva integração do território nacional. Para sustentar estas diretrizes o Governo Federal criou o Programa de Integração Nacional (PIN) com a promulgação do Decreto-Lei no 1.106, de 16 de junho de 1970. É importante ressaltar que a região Centro-Oeste não estava contemplada neste programa, entretanto, para integrar a Amazônia à Região Concentrada era preciso superar os gargalos existentes nesta região - Centro-Oeste. Nesta perspectiva, o Governo Médici, por meio da Lei no 5.727, promulgada em 4 de novembro de 1971, apresenta as diretrizes do Primeiro Plano Nacional de Desenvolvimento (I PND), a ser implantado no período 1972-1974.

No Estado de Goiás, partes desses investimentos estiveram diretamente relacionados à criação do Programa de Desenvolvimento do Centro-Oeste (PRODOESTE), cujo objetivo era desenvolver e modernizar a agricultura e pecuária da região. Além do PRODOESTE, o Ministério do Interior, por meio da Superintendência de Desenvolvimento da Região Centro-Oeste (SUDECO), desenvolveu o Plano de Desenvolvimento Econômico-Social do Centro-Oeste (PLADESCO). Com a execução destes planos e programas, a intensificação da densidade técnica, e dos avanços do meio técnico-científicoinformacional a rede urbana regional tornou-se mais complexa e intensificou a dinâmica territorial.

Recentemente, alguns pesquisadores abordaram, em certa medida, a realidade aqui contemplada, com destaque para os trabalhos de Cardoso (2005), Silva (2008), Castilho (2009) e Freitas e Mello (2014). Além dos autores citados, vale destacar as obras clássicas de Ianni (1977), Santos (1994) e Corrêa (1997).

Portanto, a organização deste artigo foi pautada em pesquisas bibliográficas, análise de documentos em arquivos públicos, documentos oficiais, leis, decretos e tratamento de informações contidas em mapas editados durante a execução dos planos e programas.

\section{Desenvolvimento}

Para facilitar a compreensão deste artigo devemos considerar a relevância dos planos e programas desenvolvidos no território nacional e o ponto de partida visa apresentar a importância do planejamento econômico no Brasil pois este foi, e continua sendo, marcado por constantes reformulações, sob o argumento de aumentar o grau de eficiência por meio do aprimoramento da racionalidade administrativa.

Desde a era Vargas, o planejamento tornou-se uma ferramenta importante para a gestão pública e, consequentemente, os governos posteriores entenderam que o referido recurso era fundamental para esta. Tal tendência foi consolidada na gestão de Juscelino Kubitschek, que, por meio do Plano de Metas, reforçou a importância do planejamento.

Na década de 1960, Planos e Programas desenvolvidos orientaram o planejamento governamental e contemplaram ações de caráter nacional que impactaram tanto internamente quanto internacionalmente. Nessa perspectiva, as ações políticas e econômicas do Governo Federal eram articuladas em escalas regionais e nacional.

No final da década de 1950 e durante a década de 1960, a Superintendência de Desenvolvimento do Nordeste - SUDENE, assim como outras Superintendências concentraram esforços para o Desenvolvimento Regional cujo objetivos eram "reduzir" as disparidades regionais, promover uma maior integração da economia nacional e dinamizar as regiões onde atuavam. 
Naquele memento, a Lei no 5.365, de 4 de dezembro de 1967, previa que as áreas sob a responsabilidade da SUDECO e da SUDAM receberiam estímulos fiscais. Havia uma complementaridade entre estas Superintendências, que exerciam um papel importante no desenvolvimento regional.

O Governo Médici, por meio da Lei no 5.727, promulgada em 4 de novembro de 1971, apresenta as diretrizes do Primeiro Plano Nacional de Desenvolvimento (I PND), a ser implantado no período 1972-1974. Nesta perspectiva, Mello (2009, p. 162) esclarece que:

No período de vigência de Planos e Programas, as atenções estavam voltadas para o espaço público. 0 espaço e as leis tornam-se elementos estratégicos e indissociáveis na condução das políticas voltadas à gestão do território nacional. Foi na articulação destes dois elementos - o espaço e as leis - que se definiu a equação para o processo de reconfiguração territorial necessária à instauração de um estado de progresso contínuo.

Ao analisar o Primeiro Plano Nacional de Desenvolvimento, fica evidente a proposta de Integração Nacional. Para efetivá-la, era preciso criar estratégias que pudessem atender às demandas regionais, tendo em vista a relação de complementariedade entre Planos e Programas de abrangência regional e nacional. Entre as ressalvas contidas no I PND, destacamos a de número 4: ela enfatiza que o Plano deveria prever a complementação das rodovias radiais, tendo como ponto de partida a Capital Federal, sediada na porção central do território brasileiro. Para reforçar esta deliberação, promulgase a Lei no 5.917, de 10 de dezembro de 1973, que aprova o Plano Nacional de Aviação.

Em meio a esta conjuntura traçada por uma efetiva atuação do Governo Federal, a região CentroOeste ganha maior visibilidade, pois era o "meio" para se alcançar o "fim": incorporar a região Amazônica à dinâmica produtiva nacional, intensificando o processo de descentralização da economia.

\subsection{O Programa de Desenvolvimento do Centro-Oeste}

A expansão da fronteira econômica possibilitou a convergência de recursos e investimentos a várias regiões do país. No Estado de Goiás, partes desses investimentos estão diretamente relacionados à criação do Programa de Desenvolvimento do Centro-Oeste (PRODOESTE), cujo objetivo era desenvolver e modernizar a agricultura e pecuária da região.

No início da década de 1970, a Companhia de Desenvolvimento do Estado de Goiás (CODEG) divulgou um relatório que continha informações socioeconômicas referentes à economia goiana contexto do PRODOESTE. Este programa foi criado pela Lei Federal $\mathrm{n}$ o 1.192 , em 8 de novembro de 1971, e buscou incrementar o desenvolvimento econômico do Sul dos Estados de Mato Grosso, de Goiás e do Distrito Federal. No art. $2^{\circ}$ desta lei consta que:

O PRODOESTE objetivará a construção imediata de uma rede rodoviária básica, prioritária, conjurada a um sistema de estradas vicinais e a uma rede de silos, armazéns, usinas de beneficiamento e frigoríficos, bem como a realização de obras de saneamento geral, retificação de cursos de água e recuperação de terras. (BRASIL, 1971b)

Os recursos destinados ao Programa foram da ordem de Cr\$ 650.000.000,00 (seiscentos e cinquenta milhões de cruzeiros) (BRASIL, 1971), divididos da seguinte forma:

a) Implantação e pavimentação da rede rodoviária básica: Cr\$460.000.000,00;

b) Construção do sistema de estradas vicinais: $\operatorname{Cr} \$ 50.000 .000,00$;

c) Construção de rede de armazéns e silos, usinas de beneficiamento e frigoríficos: Cr\$ 
90.000.000,00;

d) Realização de obras de saneamento geral: $\operatorname{Cr} \$ 50.000 .000,00$.

A divisão dos recursos evidencia que aproximadamente $78 \%$ do montante disponibilizado ao PRODOESTE foi direcionado ao setor de transportes e o restante ao setor produtivo. Estas ações, agregaram uma maior densidade técnica e dinamizou a modernização produtiva regional. 0 relatório apresentado pela da CODEG (1972, p. 10) delimita a área atendida pelo programa: "a referida região goiana do PRODOESTE, assim entendida, envolve 171 municípios, somando uma área de 356. 243 $\mathrm{Km} 2$, ou seja, cerca de $55,48 \%$ do território estadual".

Entre as três grandes regiões goianas do programa destacadas no mapa 01, a região Central contempla o município de Ceres. Nessa perspectiva, o relatório produzido pela CODEG (1972) menciona que dentro do PRODOESTE, planejava-se a execução de obras de drenagem, irrigação e defesa contra inundações nas regiões de Rio Verde, na Região Sul-Sudeste do Estado, em Ceres; e Anápolis-Goiânia, na Região Central.

Os mapas produzidos pela CODEG (1972) contemplam o destino do fluxo de determinados produtos agrícolas. 0 mapa temático vinculado à Bacia Leiteira (Mapa 02), bem como o de Produção de Milho (Mapa 03), indicam que Ceres ocupava uma posição de relevo na dinâmica econômica do estado de Goiás.

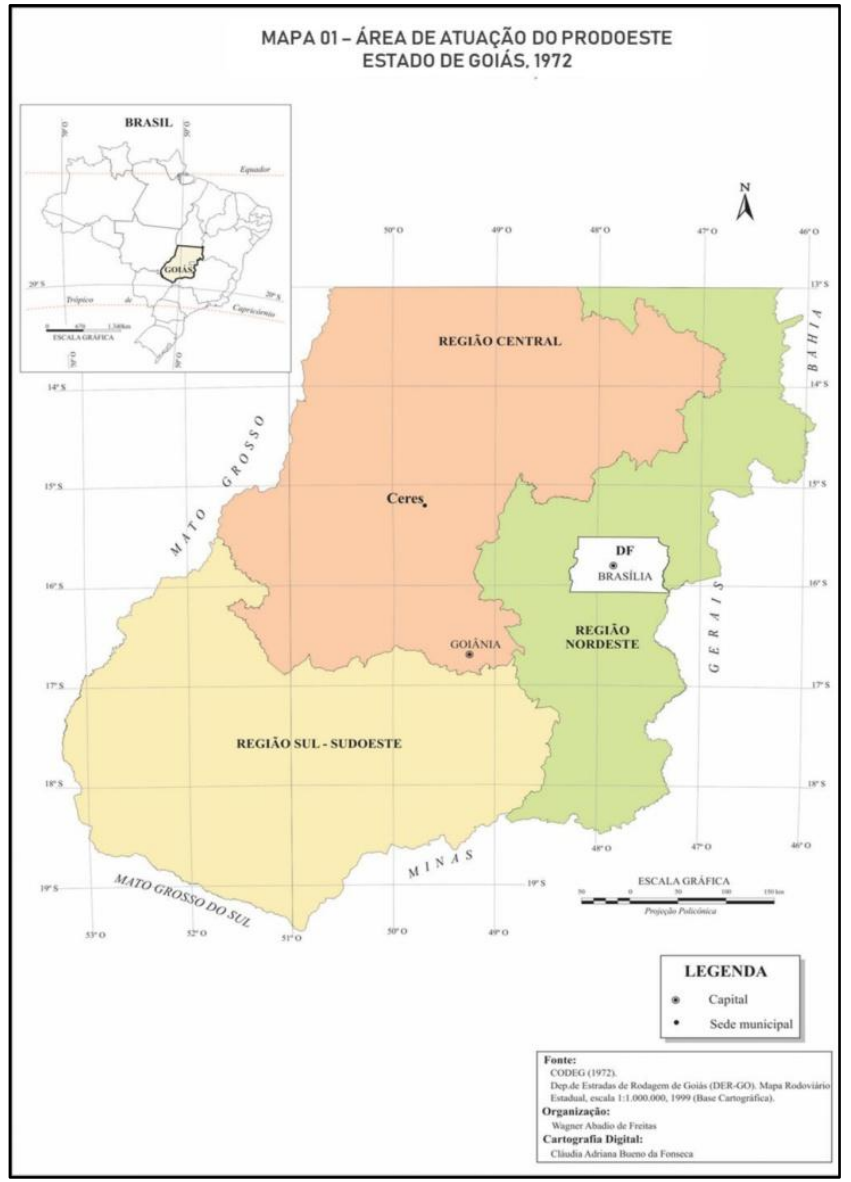

Fonte: CODEG (1972, p. 11) 


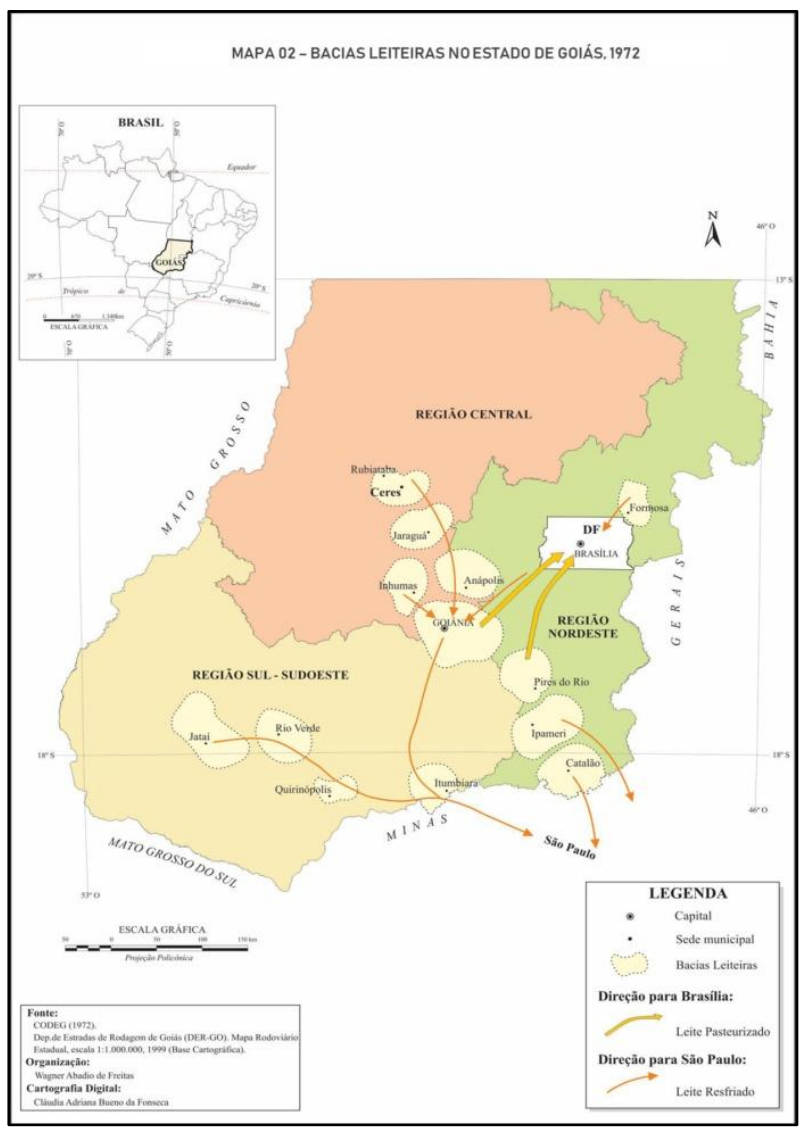

Fonte: CODEG (1972, p. 194).

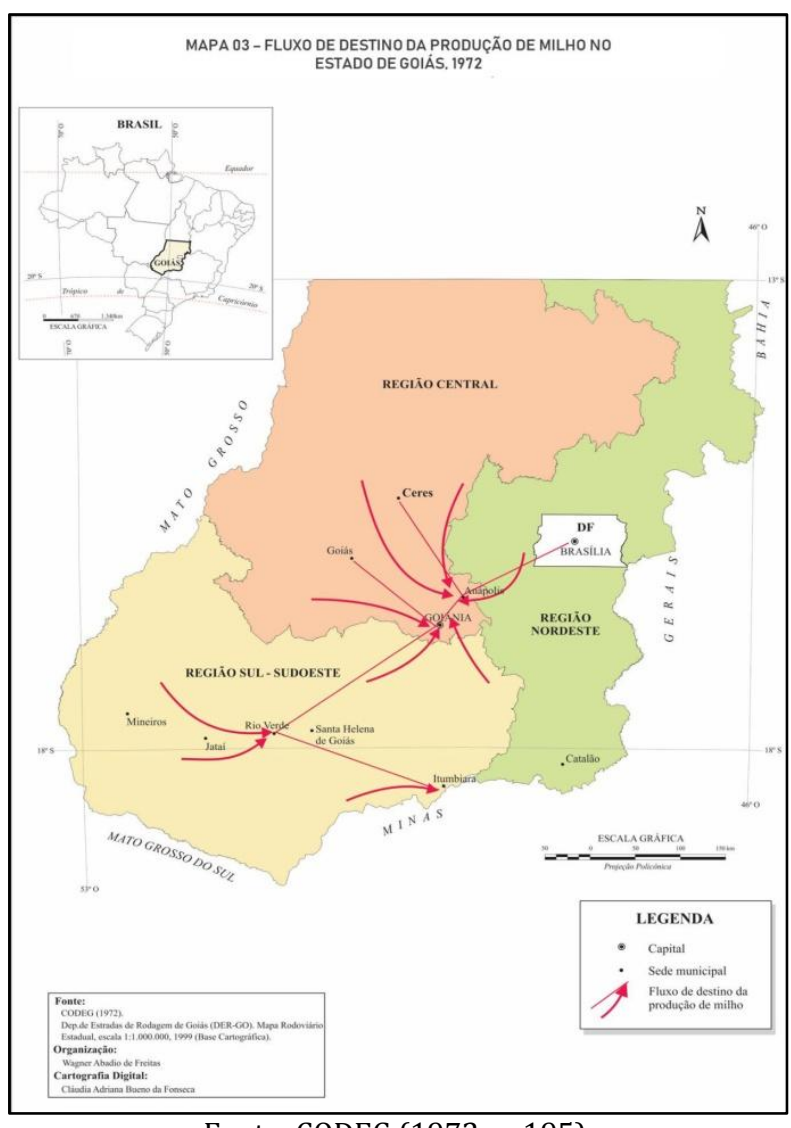

Fonte: CODEG (1972, p. 195). 


\subsection{Plano de Desenvolvimento Econômico e Social do Centro-Oeste}

Além do PRODOESTE, o Ministério do Interior, por meio da Superintendência de Desenvolvimento da Região Centro-Oeste (SUDECO), desenvolveu o Plano de Desenvolvimento Econômico-Social do Centro-Oeste (PLADESCO). As metas previstas abrangiam o biênio 1973/74, e contemplavam o conceito de planejamento dinâmico, compatível com o I Plano Nacional de Desenvolvimento (BRASIL, 1973). Os principais objetivos eram:

1) Crescimento Econômico;

2) Crescimento do Setor Produtivo;

3) Expansão do Emprego;

4) Expansão dos Equipamentos Urbanos;

5) Progresso Social e Distribuição de Renda.

Para alcançar os objetivos elencados, o Estado direcionou recursos financeiros aos setores sociais e de infraestrutura. A infraestrutura teve como carro chefe o setor de transportes e a região CentroOeste passou a ser vista como "uma das melhores opções para a conquista racional da Amazônia, e a rede básica rodoviária como um dos instrumentos mais importantes na execução desta estratégia de integração nacional" (BRASIL, 1973).

A proposta apresentada pelo PLADESCO para a integração do território nacional era composta por três sistemas rodoviários fundamentais: 1) o Sistema de Penetração; 2) Sistema de Apoio; 3) Sistema Alimentador. O PLADESCO estava diretamente vinculado às ações do Plano Nacional de Aviação, apresentado no ano de 1973.

Nesse sentido, o Sistema de Penetração - constituído pelas rodovias longitudinais - evidencia a importância da BR-153 (Belém/Brasília) e da BR-165 (Cuiabá/Santarém), cujas diretrizes implantadas ou projetadas seguem o sentido sul-norte. O Sistema de Apoio, composto pela BR-262 (trecho Três Lagoas/Corumbá) a BR-070 (Brasília/Cuiabá/Cáceres), alguns trechos da BR-060 e da BR-364 e as diretrizes da BR-242, é constituído pelas rodovias transversais e diagonais articuladas com o Sistema de Penetração. A conjugação de sistemas de objetos técnicos, materializados no território da região Centro-Oeste, fez com que esta fosse incorporada pela região concentrada. Os Mapas 04, 05 e 06, a seguir, destacam os Sistemas (Viário, de Comunicação e Elétrico) existentes na região no ano de 1973.

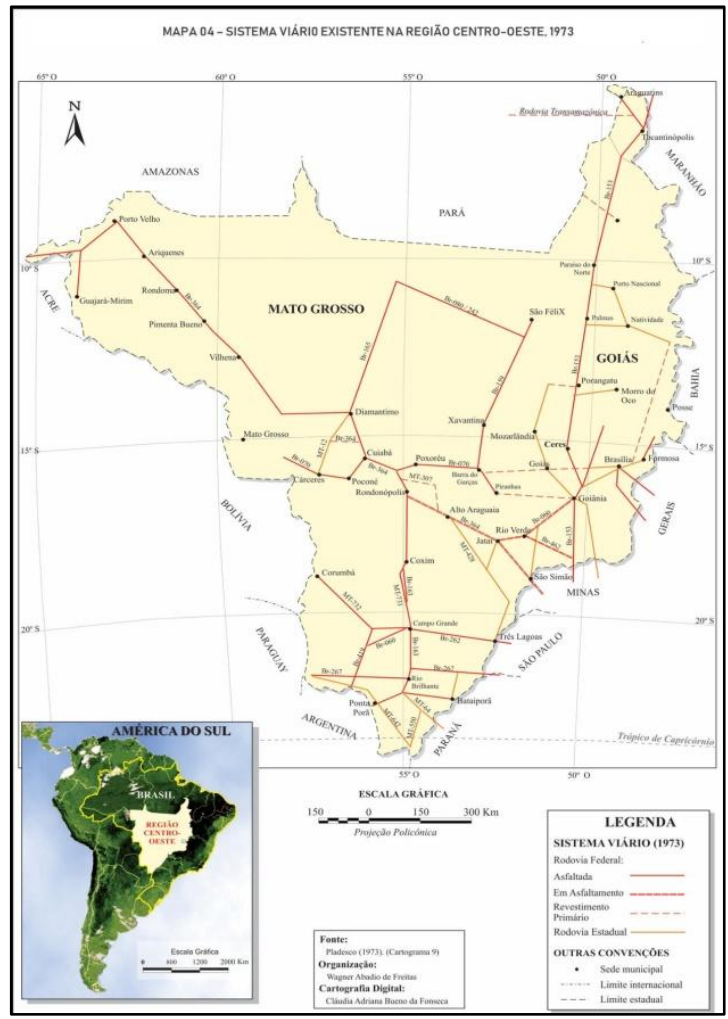

Fonte: PLADECO (1973, p. 69). 


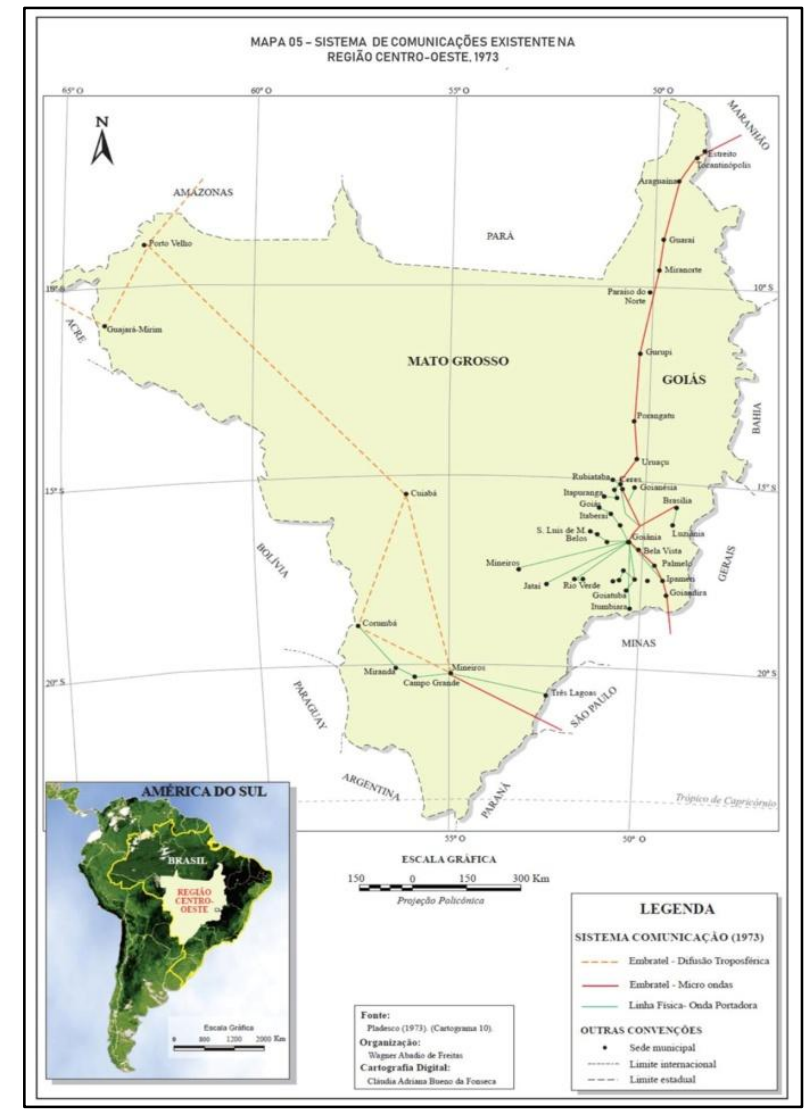

Fonte: PLADESCO (1973, p. 72).

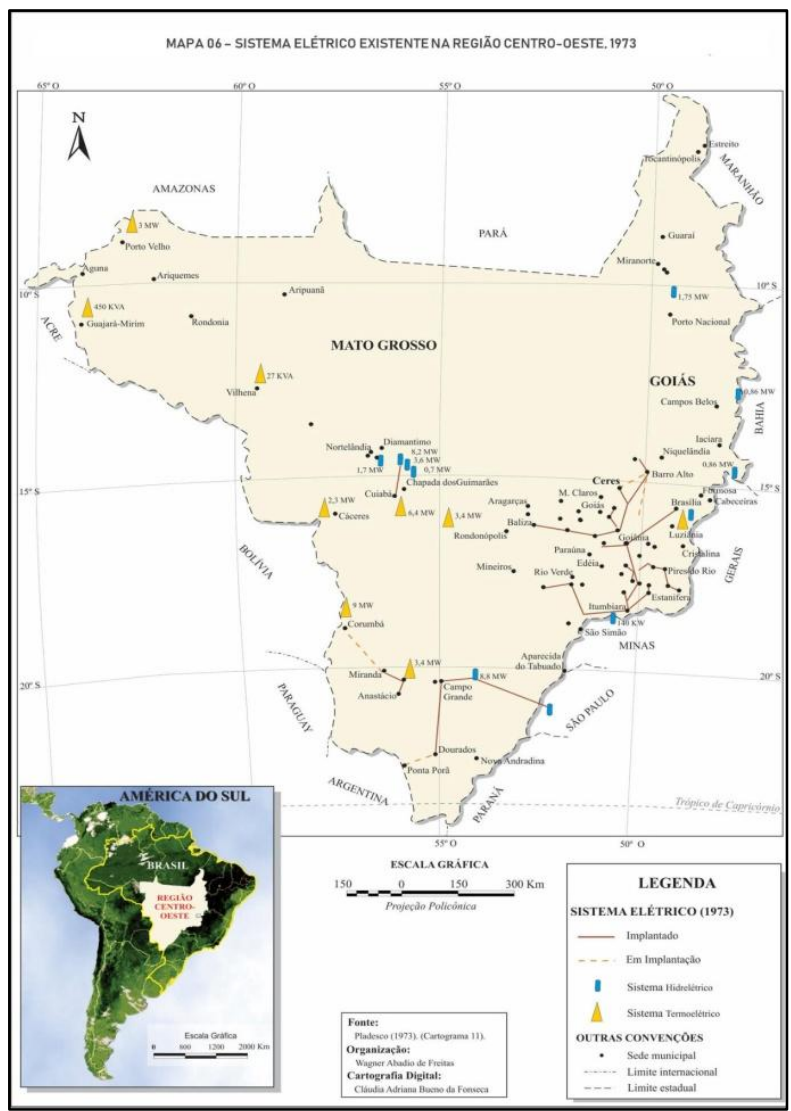

Fonte: PLADESCO (1973, p. 75). 
As informações contidas nos mapas permitem inferir que os avanços técnicos foram implementados a partir de bases científicas, com a intenção de viabilizar fluxos de capital, mercadorias, pessoas e de informações relevantes para a gestão de um processo cada vez mais complexo.

União entre ciência e técnica que, a partir dos anos 70, havia transformado o território brasileiro revigora-se com os novos e portentosos recursos da informação, a partir do período da globalização e sob e égide do mercado. E o mercado, graças exatamente à ciência, à técnica e à informação, torna-se um mercado global. 0 território ganha novos conteúdos e impõe novos comportamentos, graças às enormes possibilidades de produção e, sobretudo, da circulação dos insumos, dos produtos, do dinheiro, das ideias e informações, das ordens e dos homens. (SANTOS e SILVEIRA, 2004, p. 52-53)

Segundo os autores (idem), a constituição do meio técnico-científico-informacional está relacionada com a redefinição dos usos do território. Os objetos técnicos existentes são implementados gradativamente, alterando as relações econômicas, sociais e políticas nas regiões incorporadas à dinâmica produtiva.

Ao compararmos os mapas do Sistema (Viário, de Comunicação e Elétrico) existente com os mapas dos mesmos sistemas projetados, percebemos uma evolução na densidade técnica presente na região Centro-Oeste. Vejam os Mapas 07, 08 e 09 a seguir.

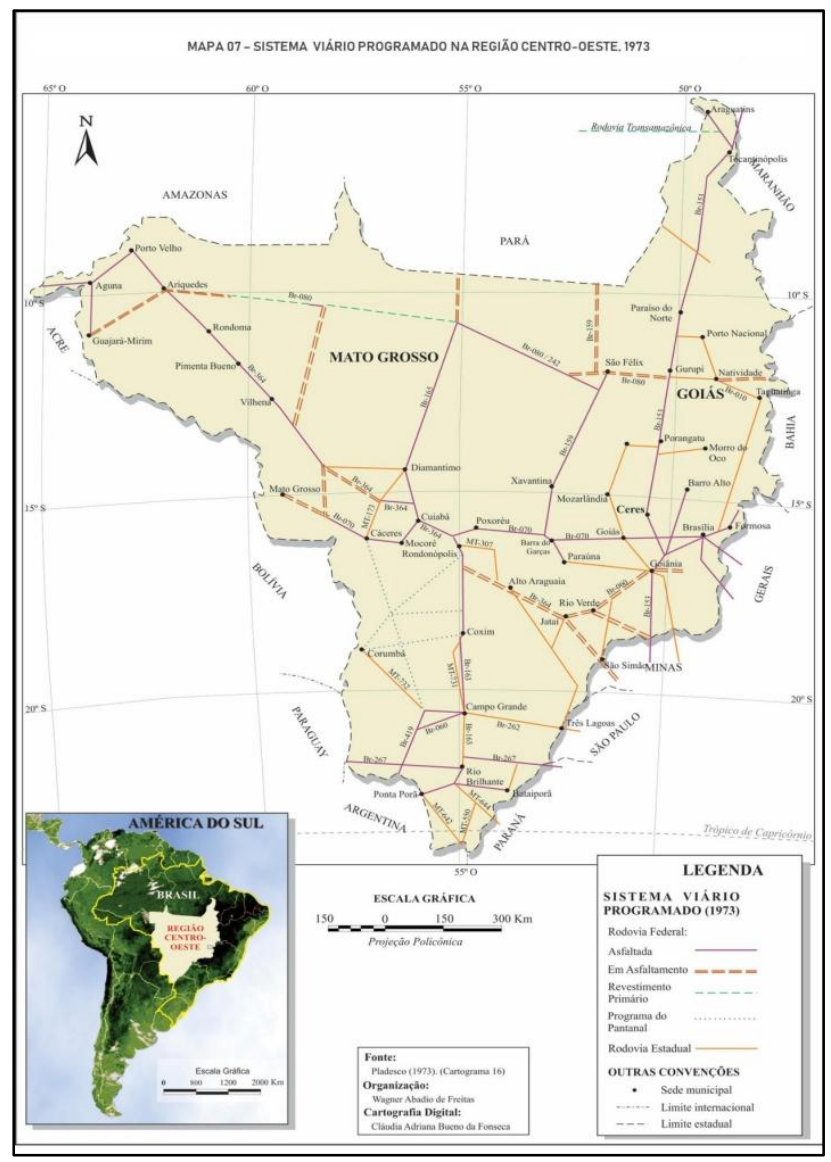

Fonte: PLADESCO (1973, p. 95) 


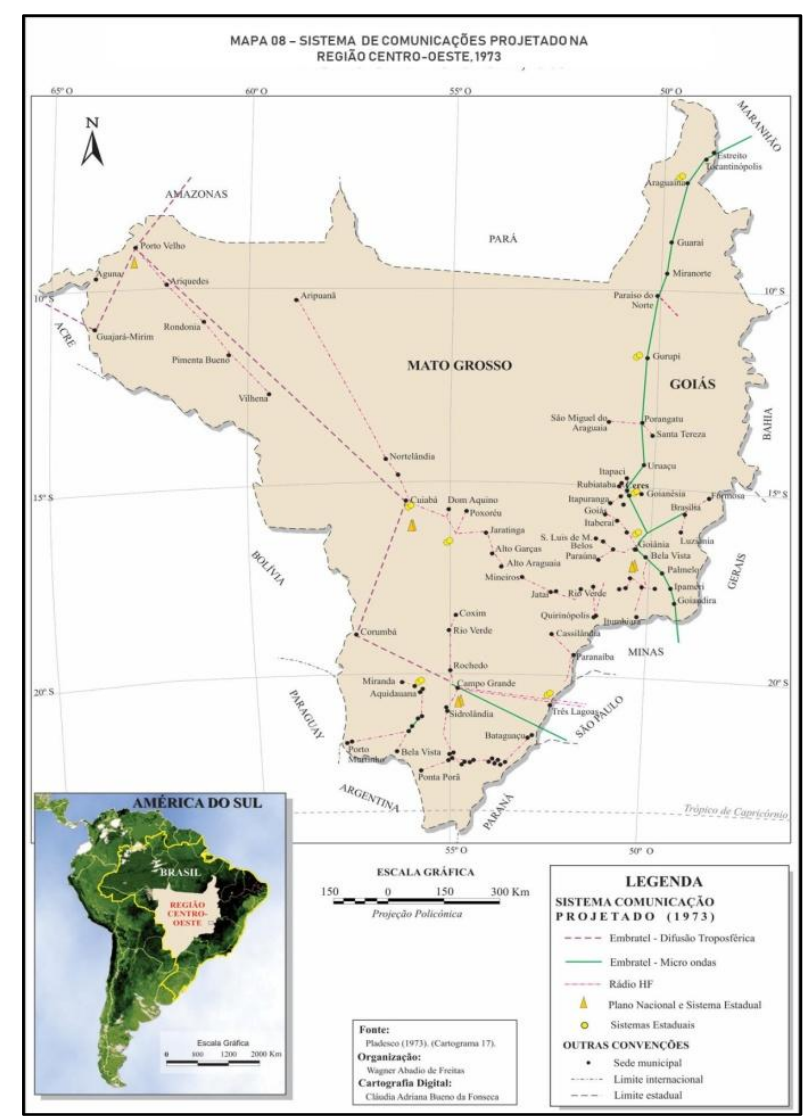

Fonte: PLADESCO (1973, p. 98).

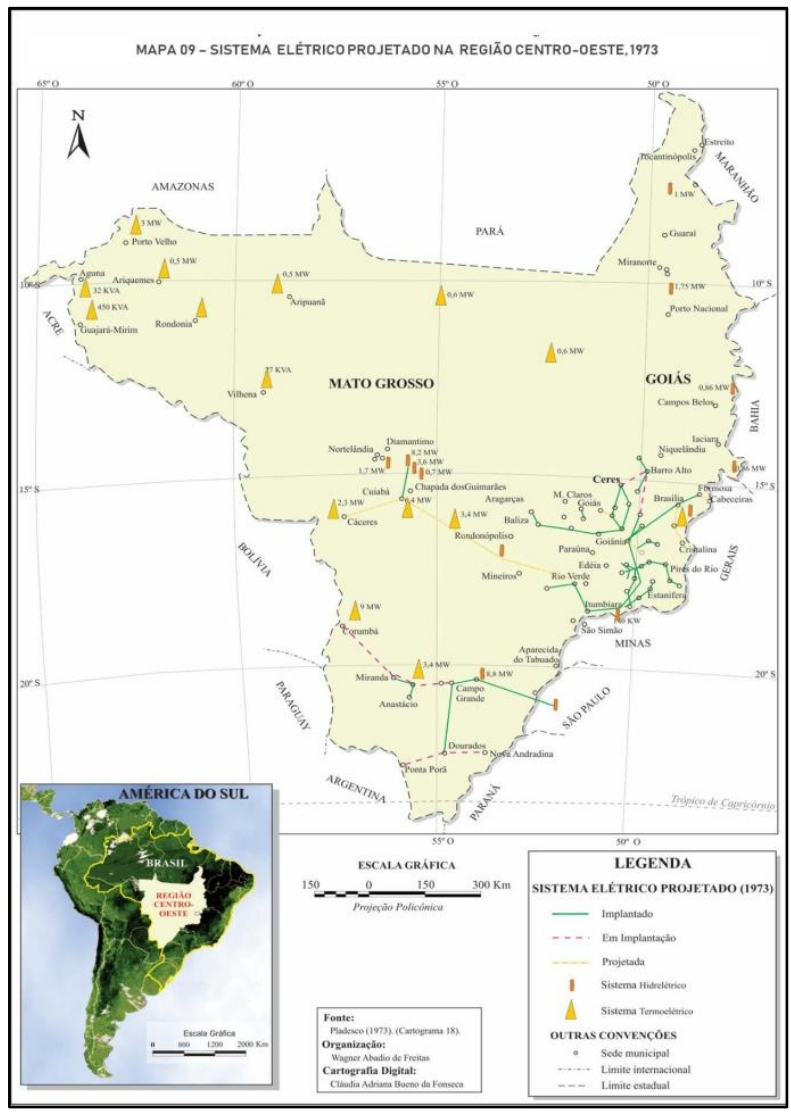

Fonte: PLADECO (1973, p. 99). 
A intensificação da densidade técnica possibilitou uma articulação mais intensa na dinâmica produtiva da região Centro-Oeste. A rede urbana em formação tornou-se mais complexa. Este movimento foi marcado por um conjunto de estratégias que atenderam tanto os interesses do Estado, quanto dos grupos políticos e econômicos situados de maneira privilegiada no processo de produção capitalista.

O Quadro a seguir demonstra a relação de complementaridade entre o desenvolvimento regional e o nacional.

Quadro 01 - Compatibilização da programação regional com as prioridades nacionais.

\begin{tabular}{|c|c|c|}
\hline Prioridades Nacionais & Programa Regional & Localização \\
\hline 1 - Integração Nacional & $\begin{array}{c}\text { 1 - Incorporação de novas áreas de } \\
\text { produção }\end{array}$ & Área de Incentivos \\
\hline 2 - Migrações Internas & $\begin{array}{c}\text { 2 - Fixação de Populações } \\
\text { Desenvolvimento Urbano }\end{array}$ & Centro-Oeste \\
\hline 3 - Corredores de Exportação & $\begin{array}{c}\text { 3 - Tecnificação da Agropecuária } \\
\text { Industrialização da Produção }\end{array}$ & Área de Exportação \\
\hline
\end{tabular}

Fonte: BRASIL. PLADESCO, 1973.

Para alcançar os objetivos propostos, a partir da compatibilização entre as prioridades nacionais e o programa regional, o PLADESCO selecionou treze Áreas-Programa.

Das treze Áreas-Programa elencadas, vale destacar a Área-Programa "Ceres-Anápolis". Na apresentação do Plano de Desenvolvimento Econômico-Social do Centro-Oeste, está registrado que "a designação da área pela nomenclatura Ceres-Anápolis teve como principal finalidade abranger um espaço geoeconômico maior, orientando-o mais no sentido norte-sul - do que o eixo Brasília/Goiânia poderia entender" (BRASIL, 1973, p. 91).

Esta ligação norte-sul esteve presente na concepção do eixo estruturante da Rodovia BelémBrasília, hoje BR-153. Esta rodovia foi e continua sendo um eixo de integração e modernização produtiva; bem como de desenvolvimento regional.

\section{Considerações Finais}

Diante das discussões e análises apresentadas é possível perceber que há uma complementariedade entre PRODOESTE e o PLADESCO, pois ambos possuem diretrizes em comum, principalmente do que diz respeito à inserção de objetos técnicos na região Centro-Oeste.

Estas intervenções e inovações fizeram parte da conjuntura econômica que o Brasil vivenciou no final da década de 1960 e início da década de 1970, marcada pelo "Milagre Econômico Brasileiro", no qual o meio "Técnico-científico-informacional" foi balizador das diretrizes modernizadoras.

Além da conjuntura econômica, é importante ressaltar a mudança demográfica ocorrida no país. De acordo com os dados divulgados pelo Instituto Brasileiro de Geografia e Estatística (IBGE), a taxa geométrica média de crescimento anual da população, segundo as grandes regiões do Brasil, apresentou dados importantes referentes à Região Centro-Oeste. No período de 1950/60, a média do crescimento nacional foi de 2,99\%, enquanto no Centro-Oeste foi de 5,36\%. No decênio seguinte, 1960/70, a média nacional foi de 2,89\%, enquanto no Centro-Oeste foi de 5,60\% (IBGE, 2001), demonstrando que a região necessitava de investimentos produtivos para atender a demanda crescente da população.

Portanto, os esforços investigativos aqui sistematizados podem ser percebidos como uma contribuição para o entendimento dos processos de ocupação, incorporação e produção do território goiano tendo em vista novos arranjos produtivos e uma reestruturação da rede urbana regional a partir da inserção de sistemas de comunicação, elétrico e rodoviário possibilitando mais fluidez ao 
território.

\section{Referências}

BRASIL, Câmara dos Deputados. Lei 5.365, de 4 de dezembro de 1967. Cria a Superintendência do Desenvolvimento da Região Centro-Oeste (SUDECO), e dá outras providências. Disponível em: < http://www2.camara.leg.br/legin/fed/lei/1960-1969/lei-5365-1-dezembro-1967-359109publicacaooriginal-1-pl.html>. Acesso em: 14 mai. 2017.

BRASIL, Câmara dos Deputados. Decreto-Lei 1.106, de 16 de junho de 1970. Cria o Programa de Integração Nacional, altera a legislação do imposto de renda das pessoas jurídicas na parte referente a incentivos fiscais e dá outras providências. Disponível em: <http://www2.camara.leg.br/legin/fed/declei/1970-1979/decreto-lei-1106-16-junho-1970375379-norma-pe.html>. Acesso em: 13 mai. 2017.

BRASIL, Senado Federal - Secretaria de Informação Legislativa. Lei 5.727, de 4 de novembro de 1971a. Dispõe sobre o Primeiro Plano Nacional de Desenvolvimento (PND), para o período de 1972 a 1974.

Disponível

em:

<http://legis.senado.leg.br/legislacao/ListaTextoIntegral.action?id=96356\&norma=120837>.

Acesso em 11 de mai. 2017.

BRASIL, Senado Federal. Decreto-Lei 1.192, de 8 de novembro de 1971. Cria o Programa de Desenvolvimento do Centro-Oeste (PRODOESTE) e dá outras providências. Disponível em: $<$ http://legis.senado.leg.br/legislacao/ListaTextoIntegral.action?id=96364\&Norma=120842>.

Acesso em 10 mai. 2017.

BRASIL, Câmara dos Deputados. Lei 5.917, de 12 de setembro de 1973. Aprova o Plano Nacional de Viação e dá outras providências. Disponível em: < http://www2.camara.leg.br/legin/fed/lei/19701979/lei-5917-10-setembro-1973-358077-publicacaooriginal-1-pl.html>. Acesso em: 10 mai. 2017.

BRASIL. Plano de Desenvolvimento Econômico-Social do Centro-Oeste - PLADESCO. Ministério do Interior, SUDECO, Brasília, 1973b.

CARDOSO, F. M. C. Cluster de saúde de CERES (GO): um resgate do seu processo de formação e expansão. 200f. 2005. Dissertação (Mestrado em Administração) - Programa de Pós-Graduação em Administração, Pontifícia Universidade Católica de Minas Gerais, Belo Horizonte, 2005.

CASTILHO, D. A dinâmica socioespacial de Ceres/Rialma no âmbito da modernização de Goiás: território em movimento, paisagens em transição. 188f. 2009. Dissertação (Mestrado em Geografia) Programa de Pesquisa e Pós-Graduação em Geografia, Universidade Federal de Goiás, Goiânia, 2009.

CODEG - Companhia de Desenvolvimento do Estado de Goiás. A Economia Goiana no PRODOESTE. Goiânia. 1972.

CORRÊA, R. L. Trajetórias Geográficas. Rio de Janeiro: Bertand Brasil, 1997. 304p.

FREITAS, W. A. MELLO, M. A. Colônia Agrícola Nacional de Goiás e a redefinição nos usos do território. Revista Sociedade \& Natureza, Uberlândia, v. 26, n. 3, p. 471-482, 2014. Disponível em < http://www.seer.ufu.br/index.php/sociedadenatureza/article/view/24883/pdf_99>. Acesso em 02 de maio. 2017.

IANNI, O. Estado e planejamento econômico no Brasil. 2. ed. Rio de Janeiro: Civilização Brasileira, 1977. 316p.

IBGE - Instituto Brasileiro de Geografia e Estatística. Tendências demográficas: uma análise dos resultados da sinopse preliminar do censo demográfico 2000 / IBGE, Departamento de População e Indicadores Sociais. - Rio de Janeiro: IBGE, 2001. 63 p.

MELLO, M. Brasília e Águas Lindas de Goiás: a loucura e a razão no processo de produção de um 
território. 2009. Tese (Doutorado em Geografia Humana) - Instituto de Estudos Sócio-Ambientais, Universidade Federal de Goiás, Goiânia, 2009.

SANTOS, M. Técnica, espaço e tempo: globalização e meio técnico-científico informacional. Rio de Janeiro: Hucitec, 1994. 190p.

SANTOS, M.; SILVEIRA, M. L. O Brasil: Território e Sociedade no início do século 21. 6. ed. Rio de Janeiro: Record, 2004. 473p.

SILVA, S. D. Os estigmatizados: distinções urbanas às margens do Rio das Almas em Goiás (19491059). 238f. 2008. Tese (Doutorado em História) - Programa de Pós-Graduação em História, Departamento de História, Universidade de Brasília, Brasília, 2008. 